\title{
An Early History of Phage Therapy in the United States: Is it Time to Reconsider?
}

\author{
Vijay H. Aswani, MD, PhD and Sanjay K. Shukla, PhD
}

\begin{abstract}
Frederick William Twort and Felix d'Hérelle independently discovered bacteriophages in 1915 and 1917, respectively. This led to the early trials of using bacteriophages to treat infectious diseases worldwide. The earliest reported use of bacteriophages therapeutically in the United States was in 1922. With the subsequent discovery of antibiotics in the 1940s, and because of disappointing results of phage therapy in the next decade, use of bacteriophages as therapeutic agents declined in western countries. This paper addresses two questions in the field: what is the historical record of the successes and failures of phage therapy in the United States and, what led to abandoning phage therapy in the United States? We examined the literature from 1915 to 1965, and we present a numerical analysis of the papers published during that period. We report key historical factors leading to a decline in the use of phage therapy in the United States by the 1950s. Since bacteriophages were first used therapeutically, several changes have occurred: increased antimicrobial drug resistance and a better knowledge of the biology of bacteriophages are important examples. Early assessments leading to the rejection of phage therapy in the United States were perhaps appropriate. However, it is time to reconsider the role of bacteriophages in treatment of bacterial infections.
\end{abstract}

Keywords: Bacteriophage; Phage therapy; History, United States, Felix d'Hérelle

$\mathrm{B}$ acteriophages are viruses that infect and replicate within bacteria and archaea. They may kill host cells by replicating intact new virion particles and lysing the host. This releases new viruses to infect adjacent cells. Alternatively, they may integrate their genome into the host's genome and replicate with the host for several generations (the lysogenic phase), reverting to a lytic phase under certain conditions. Bacteriophages are also referred to as phages ${ }^{1}$ and their application to treating bacterial infections as 'phage therapy.'

Frederick William Twort ${ }^{2}$ and Felix d'Hérelle ${ }^{3}$ discovered bacteriophages independently in 1915 and 1917, respectively.
Twort described a putative 'ultra-microscopic virus' from cultures of 'white micrococcus' he isolated from cultures of vaccinia virus. In hindsight, it would seem that the isolated lytic phages were bacteriophages against Staphylococcus species that were contaminants in a vaccinia virus culture.

F. H. d'Hérelle, on the other hand, isolated bacteriophage with activity against the Shigella bacillus from the stools of individuals recovering from bacillary dysentery. Abedon et $\mathrm{al}^{4}$ showed that even before their discovery, there were hints of the existence of bacteriophages, a period described as bacteriophage prehistory. The first clinical application of bacteriophages was by Felix d'Hérelle in $1919,{ }^{5}$ with the first
Corresponding Author: Vijay H Aswani, MD, PhD, Department of Internal Medicine \& Pediatrics, University at Buffalo, 1001 Main St., Buffalo, NY 14203, Email: vaswani@buffalo.edu
Received: July 20, 2020

Ist Revision: November 30, 2020

2nd Revision: April 21, 2021

Accepted: April 22, 2021

doi: $|0.3| 2|/ \mathrm{cmr} .202| .1605$ 
reported use in the United States in $1922 .{ }^{6}$ The period from the early 1920 s to the late 1930 s saw an increasing use of bacteriophages to treat infectious diseases worldwide. This history is summarized by d'Hérelle in his 1931 paper $^{7}$ and by Abedon et al in their review. ${ }^{8}$

Concurrent with the advent of commercial antibiotics in the 1940 s, there was a decline in the use of bacteriophages as therapeutic agents in western countries, especially the United States. Instead, studies on bacteriophages shifted to furthering an understanding of their biology. The use of phages as therapeutic agents continued unabated, however, in Eastern Europe and Russia.

What then does history speak of the successes and failures of phage therapy in the United States? While there have been at least a couple of papers describing the history of phage therapy, ${ }^{9,10}$ we chose to focus this study on phage therapy in the United States to answer these questions.

\section{Methods}

We chose to examine the scientific literature from 1915 through 1965 to investigate the rise and fall of phage therapy. The date 1915 corresponded to the earlier discovery date of bacteriophages, and 1965 coincided with the year end of the

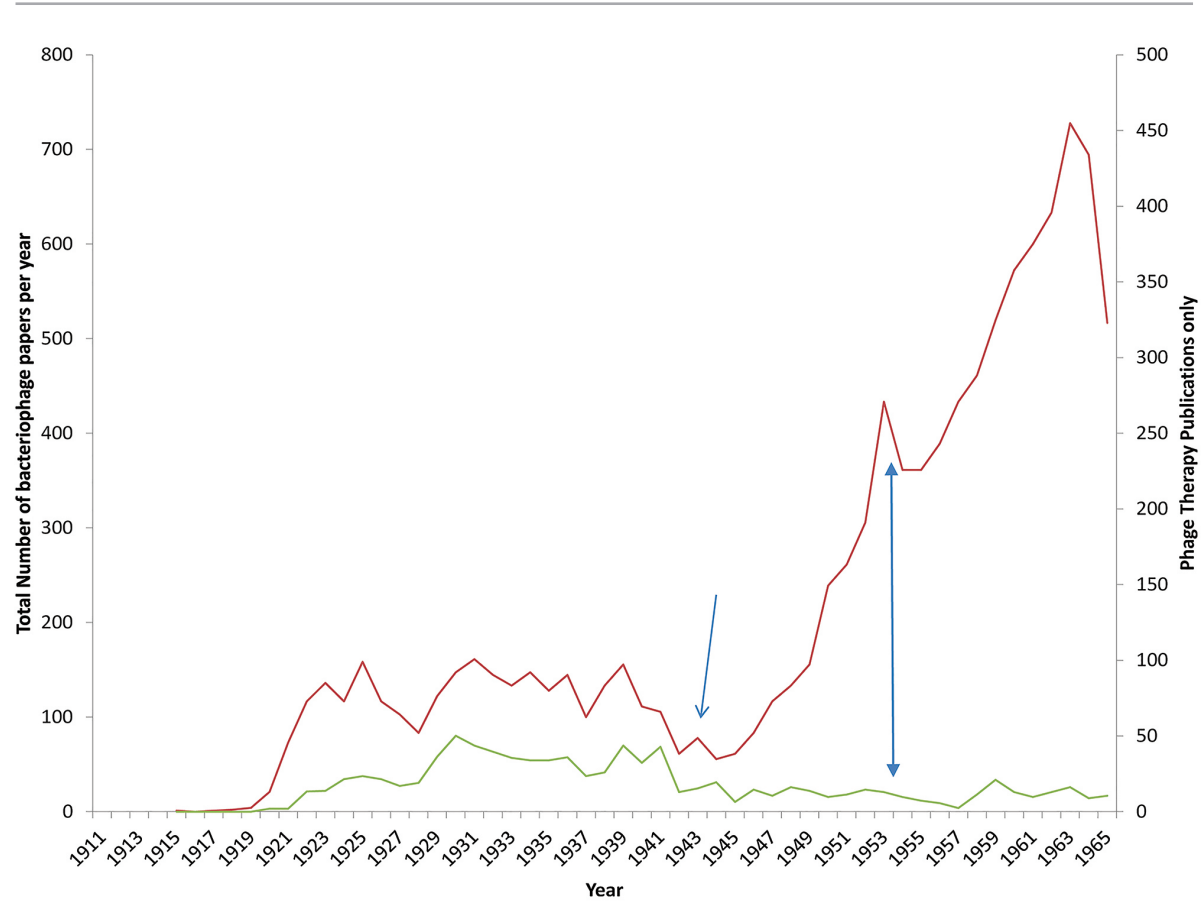

Figure 1. The number of bacteriophage scientific publications in the scientific literature by year according to Raettig in his bibliographies ${ }^{11,12}$ with the total number of papers shown in red and the phage therapy publications shown in light green. The single-headed arrow refers to the fall in numbers of scientific publications possibly from the Great Depression or World War II. The double-headed arrow show the large difference in the number of publications dealing with phage therapy compared with the total number of papers on bacteriophages extensive bibliographies assembled by Raettig. ${ }^{11,12}$ We also performed an Index Medicus search on the period 1915 to 1965. We conducted a PubMed search using the MeSH keyterm 'bacteriophage' to obtain counts of articles published by year and a separate search filtering for 'human' and 'Clinical Trial'. The latter was to attempt to identify published results of clinical trials, especially in the last several decades.

\section{Results}

From their discovery onwards, there was a rise and fall in articles on bacteriophages published in the scientific literature between 1915 and 1965. Figure 1 shows the relative decline (light green) of phage therapy publications after about 1940 . It also shows a widening gap with time between the total number of papers on bacteriophages (red line) and the papers on phage therapy (light green line) (gap indicated by double headed arrows). Figure 2 shows the number of articles indexed in Index Medicus by year, showing the total bacteriophages publications in each year in blue and those from the United States in red. The overall trend in number of U.S. publications was similar to that of the total number of publications in Index Medicus. The only difference noted was an earlier global peak in publications (in 1930) versus 1932 for U.S. publications. Table 1 compared articles grouped according to topics in the period 1915-1955 with the later period of 1956-1965. Note the significant decline in studies of phage therapy and prophylaxis $(13.8 \%$ in the initial period to $1.9 \%$ in the later period). There was also a shift towards more studies on phage biochemistry increase from $14.9 \%$ to $18.2 \%$, genetics ( $11.6 \%$ to $18.5 \%)$ and studies on lysogeny (increase from $8.3 \%$ to $12.5 \%)$.

\section{Early Phage Therapy Worldwide}

Very soon after discovery, d'Hérelle was probably the first to attempt to use bacteriophages therapeutically in 1919. ${ }^{5}$ d'Herelle and several hospital interns at the Hôpital des EnfantsMalades in Paris ingested a Shigella phage cocktail to check its safety. He then administered it to a 12-year-old boy with severe dysentery. The boy's symptoms cleared up after a single dose, and he fully recovered within a few days. d'Herelle subsequently administered a single dose each of the phage cocktail to three additional patients who also recovered within 24 hours of the administration. In 1923, d'Hérelle assisted with the founding of the Eliava Institute of Bacteriophage, Microbiology and 


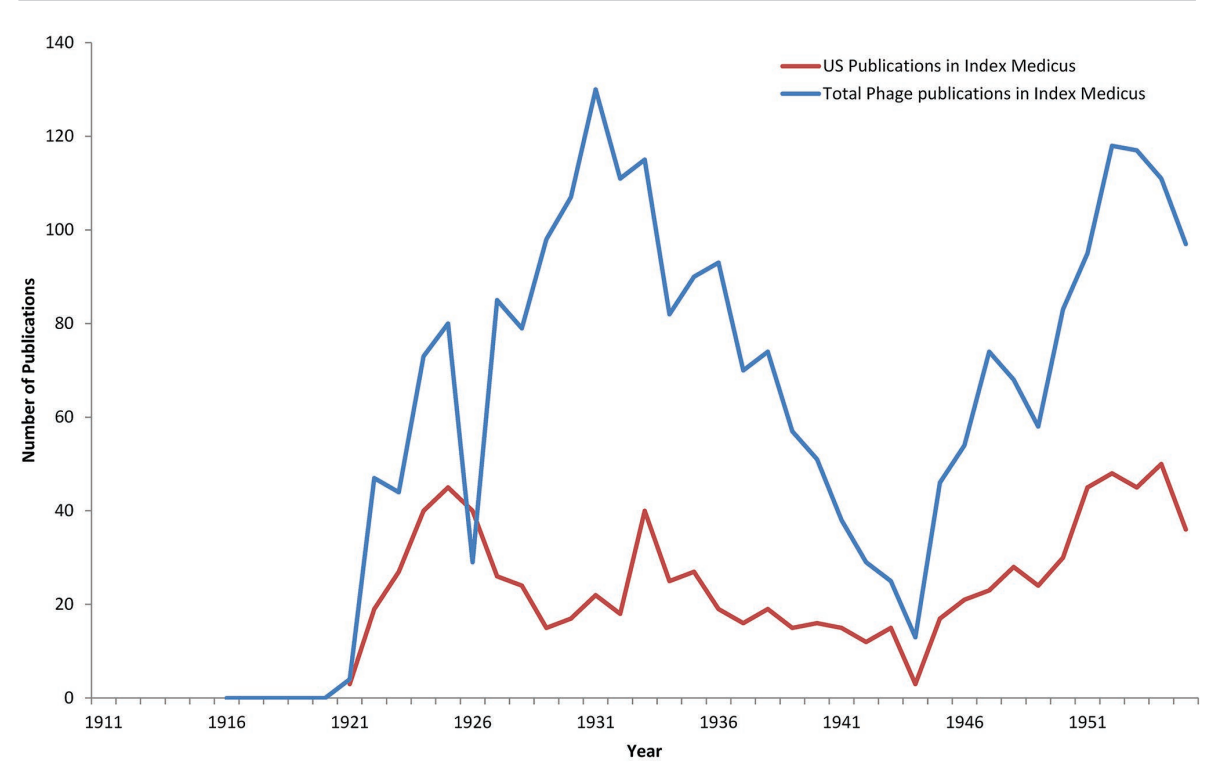

Figure 2. Graph of number of publications on bacteriophages indexed in Index Medicus showing how U.S. publications mirrored total publications. The fall in numbers of publications correspond to the Great Depression (1929 to 1941).

Virology, ${ }^{13}$ which became a major center for the development of therapeutic phages worldwide, and still is today. He also developed the Laboratoire du Bacteriophage in France in 1929..$^{5}$ d'Hérelle embarked on several clinical trials of bacteriophage therapy, including a large-scale trial of phages against cholera in India, ${ }^{5}$ where he reported favorable results. ${ }^{14}$ In 1927, d'Herelle and colleagues examined 33 patients. These patients were treated with the conventional treatment of fluids and salts; 13 patients died (mortality of 40\%). The mortality rate was $30 \%(7 / 23)$ at a Calcutta hospital and approximated the 1926 cholera mortality rate of $27 \%$ at the same facility. There were 16 patients with cholera treated with a bacteriophage preparation, giving them 2 ounces of phage lysate each by mouth. None of these patients died. The study was expanded later that year. A total of 124 cholera patients did not receive the bacteriophage treatment, with a death rate of $63 \%$. There were 74 patients who received the phage treatment, and their death rate was $8 \%{ }^{14}$

\section{Bacteriophage History in the United States}

\section{Phage Therapy}

The first use of bacteriophage therapy in the United States was in $1922^{6}$ by Davison; however, he concluded that the bacteriolysant (phages) had no therapeutic effect when administered to 12 children with dysentery. Morton and Engley ${ }^{15}$ reviewed the article and reported that 2 of the 12 children were negative for Shigella spp, and the number of cases was too small to justify any statement on the ineffectiveness of dysentery phage in children. Other workers in the United States were able to obtain results showing efficacy of bacteriophages. ${ }^{16-18}$ Spence and McKinley $^{16}$ reported treating 19 cases of bacillary dysentery with 2 deaths in the treatment group versus 5 out of 12 cases in the control group. They also noted the average time of recovery was 5.8 days in the treatment group versus 12.8 days in the control group. Larkhum ${ }^{17}$ described using

Table 1. Papers published in the early and late periods in the scientific literature worldwide showing their distribution in different areas of bacteriophage study*

\begin{tabular}{|c|c|c|c|c|}
\hline \multirow{2}{*}{ Topic } & \multicolumn{2}{|c|}{$1917-1955$} & \multicolumn{2}{|c|}{$1956-1965$} \\
\hline & No. & $\%$ & No. & $\%$ \\
\hline $\begin{array}{l}\text { Reviews, studies of a general nature or contributions to the } \\
\text { classification }\end{array}$ & 858 & 15.2 & 433 & 7.7 \\
\hline Studies on the epidemiological utilization phages & 699 & 12.4 & 1363 & 24.1 \\
\hline Studies of phage therapy and prophylaxis & 782 & 13.8 & 106 & 1.9 \\
\hline Studies concerning the morphology of phages & 192 & 3.4 & 222 & 3.9 \\
\hline Studies concerning the mechanism of reproduction of phages & 756 & 13.4 & 523 & 9.2 \\
\hline Studies on the biochemistry of phages & 841 & 14.9 & 1030 & 18.2 \\
\hline Studies into the immunity and serology in phages & 250 & 4.4 & 117 & 2.1 \\
\hline Studies on lysogeny and bacteriocinogeny & 471 & 8.3 & 705 & 12.5 \\
\hline Studies concerning phage genetics & 655 & 11.6 & 1046 & 18.5 \\
\hline Studies in working techniques in phage research & 151 & 2.7 & 199 & 3.5 \\
\hline TOTAL & 5655 & 100.0 & 5744 & 100.0 \\
\hline
\end{tabular}

*Note that between 1917-1955, papers on phage therapy made up $13.8 \%$ of all papers published on bacteriophages. This number fell to $1.9 \%$ in the period $1956-1965$ (adapted from Raettig ${ }^{11,12}$ ). 


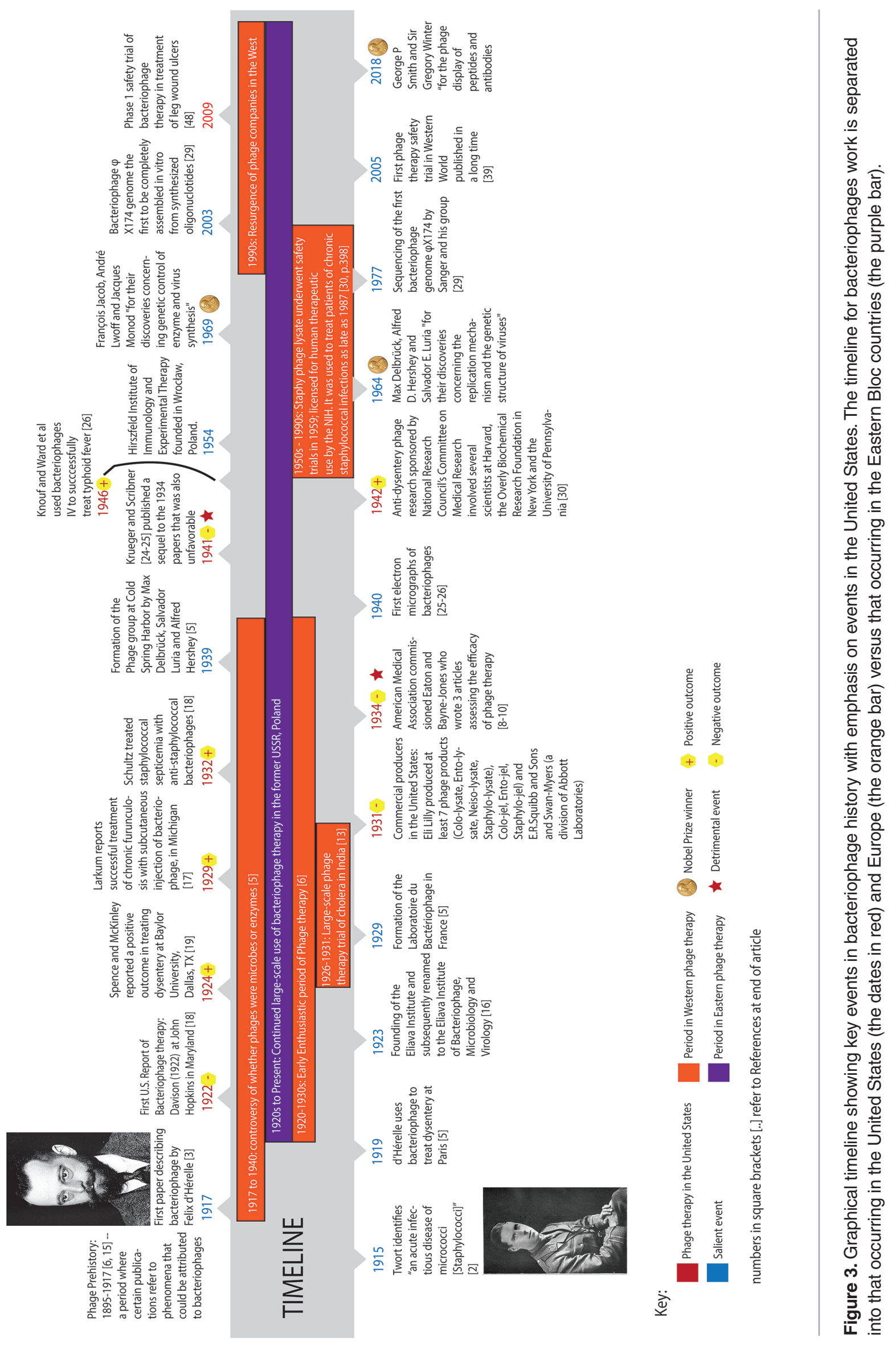


bacteriophages in more than 300 cases of furunculosis, more than 50 cases of other skin infections, and osteomyelitis with success. Schultz ${ }^{18}$ described using bacteriophages successfully in treatment of dental infections.

By 1931, major U.S. companies like Eli-Lilly \& Co, E.R. Squibb \& Sons, and Swan-Myers (a division of Abbott Laboratories) began to produce commercial phage preparations for therapeutic use. Straub and Applebaum ${ }^{19}$ evaluated products from these three companies. Eli Lilly's product was in gel form, while the other two companies' products were fluid filtrates. The products were meant to treat infections caused by staphylococci and 'colon bacillus' (Escherichia coli). The products were analyzed by incubating them with host bacteria including several laboratory strains and some strains isolated from patients with bacterial endocarditis. They looked for lysis of bacteria, scoring the results in a scale ranging from 0 to $4+$. Filtrates of the mixture were re-tested again in a fresh batch of bacteria. The authors' rationale was that bacteriophage propagate and were filterable. Therefore, they expected successive generations to yield the same positive results as the first incubated sample. With Eli Lilly's product, inhibition of growth of the host bacteria in the first generation was observed in some products tested, but the effect diminished with subsequent generations. This suggested to the authors that the bactericidal effect of the original preparation may have been due to something other than bacteriophage, such as a preservative.

The product of E.R. Squibb \& Sons did yield positive results that improved with subsequent generations of filtrates, suggesting the presence of active bacteriophage. However, they analyzed two batches, and the results varied a great deal between them.

The Staphylococcus product of Swan-Meyers yielded a potent staphylococcal bacteriophage by similar testing. The fluid staphylococcus bacteriophage revealed, according to the authors, 'a genuine and potent bacteriophage which lysed only the staphylococcus' and contained no preservative. The titers measured rose from $10^{-2}$ in 4 hours to $10^{-7}$ in 24 hours and $10^{-9}$ in 48 hours. In contrast, their staphylococcus-colon bacillus product yielded only a 'poor colon bacteriophage.'

Figure 3 summarizes various phage therapy papers reporting work done in the United States with positive (phages cured the infection they were being used to treat) and negative (phages did not treat the infection successfully) results published in the period from 1915 to 1965 . Figure 3 also shows a brief history of bacteriophages in a timeline. The U.S. history of bacteriophages is displayed in the context of bacteriophage history in general. Salient events in the U.S. history of bacteriophages encompassing both milestones in phage therapy and phage biology are shown.

In response to a growing debate on the utility of phages and the interest of industry, the American Medical Association commissioned Eaton and Bayne-Jones to report on the efficacy of phage therapy. This was published in JAMA in $1934 .^{20-22}$ The stated purpose of the review was to "present summaries and discussions of aspects of bacteriophages and to serve as a basis for a survey of the status of some of the commercial preparations.' The aspects the authors chose to focus on were: (1) the experimentally determined facts related to the bacteriophage phenomenon; (2) the laboratory and clinical evidence for and against the therapeutic usefulness; and (3) the relation of so-called antivirus to materials containing bacteriophages.

Citing 151 references, the authors listed seven conclusions, stated in italics and between single quotation marks, with our comments following:

1. 'Experimental studies of the lytic agent called 'bacteriophage' have not yet disclosed its nature. D'Herelle's theory that the materiel is a living virus parasite of bacteria has not been proved. On the contrary, the facts appear to indicate that the materiel is inanimate, possibly an enzyme.' History has proved this conclusion wrong. Bacteriophages are viruses.

2. 'Since it has not been shown conclusively that the bacteriophage is a living organism, it is unwarranted to attribute its effect on cultures of bacteria or its possible therapeutic action to a vital property of the substance.' Once again, history has proved this conclusion wrong.

3. 'While bacteriophage dissolve sensitive bacteria in cultures and cause numerous modifications of the organisms, its lytic action in the body is inhibited or greatly impeded by blood and other body fluids.' The authors cited several studies to support this; however, studies done after the publication of their review with better controls and purer bacteriophage preparations have contradicted their conclusion (see references 45 through 49 discussed later in this article for examples).

4. 'The materiel called bacteriophage is usually a filtrated of dissolved organisms, containing, in addition to the lytic principle, antigenic bacterial substances, products of bacterial growth and constituents of the culture medium. The effects of all these components must be taken into consideration whenever therapeutic action is tested.' This conclusion was certainly valid at the time of the authors' publication, although, more recent studies have remedied this criticism. (Once again, see references 45 to 49 discussed later for examples of studies using highly purified bacteriophage preparations).

5. 'A review of the literature on the use of bacteriophage in the treatment of infections reveals that the evidence for the therapeutic value of lytic filtrates is for the most part contradictory. Only in the treatment of local staphylococcic infections and perhaps cystitis (due to colon bacilli and staphylococci) has evidence at all convincing been presented.' This conclusion was an accurate assessment of the many reports reviewed by the authors. They also cited the lack of adequate controls and the impure nature of the 
bacteriophage preparations used as reasons for the contradictory findings.

6. 'There is no evidence that lysis or killing of bacteriophage occurs in vivo, except possibly in the bladder and in walled-off spaces, where little exudate is present and where irrigation with large amounts of bacteriophages can be used. 'This was an accurate conclusion based on the reports the authors reviewed in their papers.

7. 'The favorable results reported may have been due to the specific immunizing action of bacterial proteins in the materiel used and to nonspecific effects of the broth filtrates.' The conclusion was speculative but possible based on the quality of bacteriophage preparations used at the time. This was reinforced by Krueger and Scribner ${ }^{23,24}$ in a follow up review published 6 years later. These significant reviews coincided with a fall in interest in bacteriophages as therapeutic agents in the United States.

While interest and belief in the efficacy of phage therapy declined, there were still intermittent efforts to continue research in their use. An anti-dysentery phage was researched from 1942 onwards by the National Research Committee on Medical Research involving a collaboration between Harvard, the University of Pennsylvania, and the Overly Biochemical Research Foundation. ${ }^{25}$ There continued to be some modest successes, such as the treatment of typhoid fever with typespecific bacteriophage used intravenously. ${ }^{26}$ Phages were used to treat chronic staphylococcal infections in the United States as late as $1987 .{ }^{25}$

\section{Phage Biology}

Interest in bacteriophages after the aforementioned papers shifted from therapeutic applications to understanding bacteriophage biology. Around 1940, future Nobel Prize laureates Max Delbrück, Salvador Luria, and Alfred Hershey founded the Phage group at Cold Spring Harbor, New York. ${ }^{27,5}$ Bacteriophages helped define DNA (versus protein) as genetic material. ${ }^{28} \mathrm{~A}$ bacteriophage was used in the work of at least three Nobel Prizes in Physiology and Medicine (1964, 1969, and 2018). The bacteriophage genome was the first genome sequenced $^{29}$ and completely assembled in vitro. ${ }^{30}$ As bacteriophages became better understood, they became employed in molecular biology laboratories and studies, evidenced by the growth in publications as seen in Figures 1 and 2 from 1945 to 1965, while simultaneously, publications on the therapeutic use of phages declined.

\section{Analysis}

Historically, the failure of phage therapy during the 1930s has been attributed to lack of knowledge on the nature of phages (whether they were microbes or enzymes). ${ }^{5}$ To put this into perspective, DNA was discovered in 1953, and the electron microscope was first used to visualize viruses in $1939^{31}$ and bacteriophage specifically in $1940 .{ }^{32}$ Without a robust understanding of the nature of bacteriophages, it should come as no surprise that there was large variation in preparations of bacteriophages and, consequently, inconsistent results of phage therapy experiments and trials. The concurrent emergence of well-defined and better-understood antibiotics in the same period led to their logical choice as antimicrobials. The period of 1939 to 1945 was a period of declining scientific publication (see Figures 1 and 2), largely due to the disruptive effects of World War II. It was also a period of increased use of antibiotics to treat war infections. The award of the 1945 Nobel Prize in Physiology or Medicine to Fleming, Chain, and Florey for penicillin signaled recognition of the impact of chemical antimicrobials over bacteriophages. There were several reasons for the rejection of phage therapy in the United States by the 1950s: (1) reports of failed therapy often due to inconsistent technique and skill in phage cultivation ${ }^{33}$ (see figure 3); (2) commercial U.S. bacteriophage preparation with little or no bacteriophage content and inconsistent performance; ${ }^{19}$ (3) an incomplete understanding of bacteriophage biology; and (4) lack of rigorous clinical trials with adequate controls. Thus, history tells us that bacteriophages were rejected for reasons that were valid in 1950 but not in 2020. Modern bacteriophage trials use adequate controls, purified bacteriophage preparations, and sophisticated data analyses. Current National Institutes of Health (NIH) funded clinical trials of bacteriophages as potential therapeutic agents can be found at the NIH website (https:/clinicaltrials. gov/ct $2 /$ results? cond $=\&$ term $=$ bacteriophage $\&$ cntry $=\&$ state $=\&$ city $=\&$ dist $=)$. The reader is also referred to the excellent literature review and analysis by Sulakvelidze et al. ${ }^{34}$

The 21 st century saw an improved understanding of bacteriophage biology and standardized methods to utilize them. Bacteriophages have been demonstrated to be constituents of normal human flora of the anterior nares, ${ }^{35,36}$ oral cavity, ${ }^{37}$ urogenital tract, ${ }^{38}$ and gut. ${ }^{39}$ Several recent studies have suggested that bacteriophages are part of microbiomes in humans. Maqsood et $\mathrm{a}^{40}$ showed transmission of bacteria from mothers to infants in the formation of their gut microbiome is affected by bacteriophages. Verbanic et $\mathrm{al}^{41}$ showed through deep sequencing that bacteriophages are part of wound microbiomes. Wang et $\mathrm{al}^{42}$ showed bacteriophages were part of the skin microbiome and there was differential bacteriophage composition noted between the microbiomes of normal and psoriasis skin. Finally, Ly et $\mathrm{al}^{43}$ showed mouth and gut microbiomes are often shared by members of the same family and bacteriophages make up a sizeable portion of these microbiomes.

The increasing bacterial resistance to antibiotics, recognition of the importance of the microbiome, and that bacteriophages make up a part of these microbiomes have led several scientists and physicians to wonder if bacteriophages could be used as therapeutic agents. Attesting to their safety and providing anecdotal evidence of efficacy is their long-standing use as therapeutic agents in Poland, Georgia, and several other Eastern Bloc countries. The Journal of the American Medical Association (JAMA) also recently published the announcement of the first FDA approved U.S. clinical trial of intravenously administered 
bacteriophage therapy on February 19, 2019. ${ }^{44}$ There are also now several U.S. companies marketing phages for therapeutic use in animals and investigating future use in humans. Bacteriophages are once again being evaluated as potential therapeutic agents. The initial results ${ }^{45-49}$ from recent trials suggest a much more positive reception this time around than in the early trial of phage therapy. In the PHAGE study $(n=43)$, Febvre et $\mathrm{al}^{45}$ used a commercial cocktail of $E$. coli-targeting bacteriophages in a double-blinded, placebo-controlled crossover trial, in which normal to overweight adults consumed bacteriophages for 28 days. They demonstrated reductions in fecal $E$. coli loads with phage consumption. Leitner et $\mathrm{al}^{50}$ reported in their randomized, placebo-controlled double-blind clinical trial $(n=474)$, that intravesical bacteriophage therapy was non-inferior to standard-of-care antibiotic treatment for treating urinary tract infections in patients undergoing transurethral resection of the prostate. Schooley et $\mathrm{al}^{47}$ reported on a method used to produce a personalized bacteriophagebased therapeutic treatment for a 68-year-old diabetic patient with necrotizing pancreatitis complicated by a multi-drug resistant Acinetobacter baumannii infection. They showed how administration of bacteriophages intravenously and percutaneously into the abscess cavities was associated with reversal of the patient's downward clinical trajectory, clearance of the A. baumannii infection, and a return to health.

\section{Conclusion}

Despite the discovery of phages in 1915, phage therapy was rejected after early use. Reasons for this included lack of early success in treating bacterial infections, discovery of antimicrobials in the 1940s, lack of high quality phage preparations in the 1930s, and a lack of understanding of phage specificity and phage resistance. With emergence of antibacterial resistance in clinically important pathogens, a better understanding of phage genomics, specificity, and their therapeutic power convinces us that there is a need to revisit phages as therapeutic agents.

\section{Acknowledgments}

We gratefully acknowledge the contributions of Barbara Bartkowiak, research librarian at the Marshfield Clinic Library in the collection of material for this paper. An early version of this paper was first presented as a poster at the American Society of Microbiology Meeting in 2014.

\section{References}

1. Ackermann HW. Phage or Phages. Bacteriophage. 2011;1(1):52-53.

2. Twort FW. An investigation on the nature of ultramicroscopic viruses. The Lancet. 1915;186: 1241-1243.

3. d'Hérelle F. Sur un microbe invisible antagoniste des bacilles dysentériques. C R Acad Sci Ser D. 1917; 165:373-375.

4. Abedon ST, Thomas-Abedon C, Thomas A, Mazure H. Bacteriophage prehistory: Is or is not Hankin, 1896, a phage reference? Bacteriophage. 2011;1:174-178.
5. Summers WC. Félix d'Herelle and the origins of molecular biology. New Haven, CT: Yale University Press; 1999.

6. Davison WC. The bacteriolysant therapy of bacillary dysentery in children: therapeutic application of bacteriolysants; d'Herelle's phenomenon. Am J Dis Child. 1922;23:531-534.

7. d'Herelle F. Bacteriophage as a treatment in acute medical and surgical infections. Bull N Y Acad Med. 1931;7:329348.

8. Abedon ST, Kuhl SJ, Blasdel BG, Kutter EM. Phage treatment of human infections. Bacteriophage. 2011;1:6685.

9. Wittebole X, De Roock S, Opal SM. A historical overview of bacteriophage therapy as an alternative to antibiotics for the treatment of bacterial pathogens. Virulence. 2014;5:226-235.

10. Summers WC. The strange history of phage therapy. Bacteriophage. 2012;2:130-133.

11. Raettig Hr. Bakteriophagie, 1917 bis 1956; Zugleich ein Vorschlag zur Dokumentation wissenschaftlicher Literatur. Stuttgart G. Fischer: 1958.

12. Raettig Hr. Bakteriophagie. 1957-1965. Stuttgart G. Fischer: 1967.

13. Chanishvili N. A literature review of the practical application of bacteriophage research. New York: Nova Biomedical Books; 2012.

14. Summers WC. Cholera and plague in India: the bacteriophage inquiry of 1927-1936. J Hist Med Allied Sci. 1993;48:275-301.

15. Council on Pharmacy and Chemistry; Morton HE, Engley FB Jr. Dysentery Bacteriophage: Review of the literature on its prophylactic and therapeutic uses in man and in experimental infections in animals. JAMA.

1945;127(10):584-591. doi:10.1001/ jama.1945.02860100028008. Available at: http://blogs. evergreen.edu/phage/files/2011/03/morton_j_a_m_a_1945 dysentery_phage.pdf. Last accessed: June 1, 2021.

16. Spence RC, McKinley EB. Therapeutic Value of the bacteriophage in treatment of bacillary dysentery. South Med J. 1924;17:563-568.

17. Larkum NW. Bacteriophage from a public health standpoint. Am J Public Health. 1929;19:31-36.

18. Schultz EW. Bacteriophage: possible therapeutic aid in dental infections. J Dental Res. 1932;12:295-310.

19. Straub ME, Applebaum M. Studies on commercial bacteriophage products. JAMA. 1933;100(2):110-113.

20. Eaton MD, Bayne-Jones S. Bacteriophage therapy: review of the principles and results of the use of bacteriophage in the treatment of infections. JAMA. 1934;103(24): 1847-1853.

21. Eaton MD, Bayne-Jones S. Bacteriophage therapy: review of the principles and results of the use of bacteriophage in the treatment of infections. JAMA. 1934;103(23):1769-1776. 
22. Eaton MD, Bayne-Jones S. Bacteriophage therapy: review of the principles and results of the use of bacteriophage in the treatment of infections. JAMA. 1934;103(25):1934-1939.

23. Krueger AP, Scribner EJ. The Bacteriophage: its nature and its therapeutic use. JAMA. 1941;116(19):21602167.

24. Krueger AP, Scribner EJ. The Bacteriophage: its nature and its therapeutic use. JAMA. 1941;116(20):22692277.

25. Kutter E, Sulakvelidze A. Bacteriophages: biology and applications. Boca Raton, FL: CRC Press; 2005.

26. Knouf EG, Ward WE, Reichle PA, et al. Treatment of typhoid fever with type specific bacteriophage: Preliminary report. JAMA. 1946;132(3):134-138.

27. Wikipedia. Phage Group. 2020. Available at: https:// en.wikipedia.org/wiki/Phage_group. Accessed Nov 23, 2020 .

28. Hershey AD, Chase M. Independent functions of viral protein and nucleic acid in growth of bacteriophage. $\mathrm{J}$ Gen Physiol. 1952;36(1):39-56.

29. Sanger F, Air GM, Barrell BG, et al. Nucleotide sequence of bacteriophage phi X174 DNA. Nature. 1977;265:

687-695.

30. Smith HO, Hutchison CA, 3rd, Pfannkoch C, Venter JC. Generating a synthetic genome by whole genome assembly: phiX174 bacteriophage from synthetic oligonucleotides. Proc Natl Acad Sci U S A. 2003;100:15440-15445.

31. Kausche GA. Pfankuch E, Ruska H. Die Sichtbarmachung von pflanzlichem Virus im Übermikroskop. Naturwissenschaften. 1939;27:292-299.

32. Ackermann HW. The first phage electron micrographs. Bacteriophage. 2011;1:225-227.

33. Brussow H. Phage therapy: quo vadis? Clin Infect Dis. 2014;58:535-536.

34. Sulakvelidze A, Alavidze Z, Morris JG, Jr. Bacteriophage therapy. Antimicrob Agents Chemother. 2001;45:649-659.

35. Aswani V, Tremblay DM, Moineau S, Shukla SK. Staphylococcus epidermidis bacteriophages from the anterior nares of humans. Appl Environ Microbiol. 2011;77:78537855.

36. Aswani VH, Tremblay DM, Moineau S, Shukla SK. Complete genome sequence of a Staphylococcus epidermidis bacteriophage isolated from the anterior nares of humans. Genome Announc. 2014;2(4):e00549-14.

37. Hitch G, Pratten J, Taylor PW. Isolation of bacteriophages from the oral cavity. Lett Appl Microbiol. 2004;39:215219.

38. Miller-Ensminger T, Mormando R, Maskeri L, et al. Introducing Lu-1, a Novel Lactobacillus jensenii Phage Abundant in the Urogenital Tract. PLoS One. 2020;15(6):e0234159.
39. Dalmasso M, Hill C, Ross RP. Exploiting gut bacteriophages for human health. Trends Microbiol. 2014;2:399-405.

40. Maqsood R, Rodgers R, Rodriguez C, et al. Discordant transmission of bacteria and viruses from mothers to babies at birth. Microbiome. 2019;7:156.

41. Verbanic S, Kim CY, Deacon JM, Chen IA. Improved single-swab sample preparation for recovering bacterial and phage DNA from human skin and wound microbiomes. BMC Microbiol. 2019;19:214.

42. Wang H, Chan HH, Ni MY, et al. Bacteriophage of the skin microbiome in patients with psoriasis and healthy family controls. J Invest Dermatol. 2020;140:182-190 e185.

43. Ly M, Jones MB, Abeles SR, et al. Transmission of viruses via our microbiomes. Microbiome. 2016;4:64.

44. Voelker R. FDA approves bacteriophage trial. JAMA. 2019;321:638.

45. Febvre HP, Rao S, Gindin M, et al. PHAGE Study: effects of supplemental bacteriophage intake on inflammation and gut microbiota in healthy adults. Nutrients. 2019;11:666.

46. Leitner L, Sybesma W, Chanishvili N, et al.

Bacteriophages for treating urinary tract infections in patients undergoing transurethral resection of the prostate: a randomized, placebo-controlled, double-blind clinical trial. BMC Urol. 2017; 17:90.

47. Schooley RT, Biswas B, Gill JJ, et al. Development and use of personalized bacteriophage-based therapeutic cocktails to treat a patient with a disseminated resistant Acinetobacter baumannii infection. Antimicrob Agents Chemother. 2018;62(12).

48. Rhoads DD, Wolcott RD, Kuskowski MA, et al. Bacteriophage therapy of venous leg ulcers in humans: results of a phase I safety trial. J Wound Care. 2009;18:237-243.

49. Bruttin A, Brussow H. Human volunteers receiving Escherichia coli phage T4 orally: a safety test of phage therapy. Antimicrob Agents Chemother. 2005;49:28742878.

50. Leitner L, Ujmajuridze A, Chanishvili N, et al. Intravesical bacteriophages for treating urinary tract infections in patients undergoing transurethral resection of the prostate: a randomised, placebo-controlled, doubleblind clinical trial. Lancet Infect Dis. 2021;21:427436.

\section{Author Affiliations}

Vijay H Aswani, MD, PhD* and Sanjay K Shukla, PhD

*Department of Internal Medicine \& Pediatrics, University at Buffalo, Buffalo, New York, USA

Center for Precision Medicine Research, Marshfield Clinic Research Institute, Marshfield, Wisconsin, USA 